\title{
Stereotactic Body Radiation Therapy as a Bridge to Transplantation and for Recurrent Disease in the Transplanted Liver of a Patient with Hepatocellular Carcinoma
}

\author{
Ali Mazloom ${ }^{\mathrm{a}} \quad$ Aram F. Hezel ${ }^{\mathrm{b}} \quad$ Alan W. Katz \\ ${ }^{a}$ Department of Radiation Oncology, and ${ }^{b}$ Division of Hematology and Oncology, \\ Department of Medicine, University of Rochester Medical Center, Rochester, N.Y., USA
}

\section{Key Words}

Hepatocellular carcinoma Stereotactic body radiation therapy · Orthotopic liver transplantation

\begin{abstract}
Hepatocellular carcinoma ( $\mathrm{HCC}$ ) is one of the most common causes of cancer mortality worldwide. Despite orthotopic liver transplantation (OLT), recurrent HCC is a major cause of morbidity. In this case report, we evaluate the efficacy of stereotactic body radiation therapy (SBRT) as a bridge to OLT and for recurrence in the transplanted liver of a patient with HCC. A 52-year-old male with a history of chronic hepatitis $C$ presented with a $1.7-\mathrm{cm}$ liver lesion radiographically consistent with $\mathrm{HCC}$, which was subsequently treated with a course of SBRT to $50 \mathrm{~Gy}$ in 5 fractions followed by OLT in 2009 . The patient had a $2.2-\mathrm{cm}$ recurrence in the transplanted liver in 2012, which was treated with SBRT to 62.5 Gy in 5 fractions. He tolerated the course of radiotherapy well with no significant radiation-related toxicity and remains in complete remission approximately 1 year after SBRT. SBRT is a safe and effective modality for the treatment of recurrent $\mathrm{HCC}$ in the transplanted liver of the same patient initially treated with SBRT as a bridge to OLT.

(c) 2014 S. Karger AG, Basel
\end{abstract}


Mazloom et al.: Stereotactic Body Radiation Therapy as a Bridge to Transplantation and for Recurrent Disease in the Transplanted Liver of a Patient with HCC

\section{Introduction}

Hepatocellular carcinoma (HCC) is the third most common cause of cancer mortality worldwide and its incidence has been rising over the past 3 decades [1]. Orthotopic liver transplantation (OLT) remains the preferred curative modality, providing a $70 \%$ five-year survival rate for patients meeting the Milan criteria [2]. Despite adherence to the criteria, approximately $15 \%$ of patients will experience a recurrence in the transplanted liver [3].

In this case report, we describe a patient with HCC who was treated with stereotactic body radiation therapy (SBRT) as initial bridge therapy prior to transplant and for subsequent recurrence in the transplanted liver. Our Institutional Research Subject Review Board does not require informed consent from patients for a case report.

\section{Case Report}

A 52-year-old male, undergoing surveillance because of long-standing hepatitis $\mathrm{C}$, was found to have a rising $\alpha$ fetoprotein (AFP) level and a new $1.7-\mathrm{cm}$ liver lesion consistent with HCC on a CT scan in October 2007. He was placed on the transplant list and underwent transarterial chemoembolization as bridging therapy in February 2008. The AFP level declined to normal, but within several months began to rise again. In August 2008, the patient was referred for SBRT.

The Novalis ExacTrac patient positioning platform (BrainLab AG, Heimstetten, Germany) was used for immobilization. Treatment planning was performed using the BrainScan system (BrainLab AG) and BrainLab treatment software. Treatment was prescribed to the $100 \%$ isodose line, with the $80 \%$ isodose line covering the planning target volume. Conformal arcs were used to deliver 50 Gy in ten 5 Gy daily fractions using 6-MV photons.

On May 10, 2009, the patient underwent an OLT. Pathologic examination of the native liver showed a $2.2-\mathrm{cm}$ necrotic mass with no viable tumor identified. He did well following transplant until March 2011, when a rise in AFP up to $328 \mathrm{IU} / \mathrm{ml}$ was found.

A CT scan revealed an enlarged pericaval lymph node, which was biopsied and showed metastatic carcinoma. The lymph node was treated in May 2011 with SBRT to a dose of 50 Gy in 10 fractions. There was a good response to treatment based on repeat imaging studies as well as a significant decline in the AFP level.

However, in August 2012 there was a rapid rise in the patient's AFP level, reaching $1,590 \mathrm{IU} / \mathrm{ml}$ by October. In an October $2012 \mathrm{CT}$ scan, a new 2.2-cm mass was seen in the left lobe of the liver and was treated with SBRT, 62.5 Gy in 5 fractions (fig. 1). At an initial followup after treatment, the lesion was stable on CT, and the AFP level had declined to $76 \mathrm{IU} / \mathrm{ml}$. The most recent CT scan, almost 1 year after treatment, shows complete resolution of the treated lesion with no new suspicious disease. Follow-up examination also did not reveal any signs of liver disease or radiation-related toxicity (fig. 2).

\section{Discussion}

HCC is the most common malignancy of the liver, and the fifth most common malignancy in the world, with an annual incidence of 14.7 per 100,000 men and 4.9 per 100,000 women $[4,5]$. OLT is the preferred modality for treatment in patients with HCC, with a reported 5year survival rate of $73 \%$ for patients meeting the Milan criteria for HCC [2]. Upon adoption of the Milan criteria for liver transplantation, the incidence of HCC recurrence significantly 
decreased, while the survival rate improved from 25 to 61\% [6]. However, despite the significant improvement in survival rates of patients with HCC following OLT over the past 20 years, recurrent HCC continues to be a major cause of morbidity. Furthermore, the major site of relapse for patients who have undergone liver transplantation is the transplanted liver. The rate of relapse in the transplanted liver is $4-39 \%$ in the different series, perhaps reflecting clinical differences of patients referred for liver transplantation [3, 7-9]. The treatment of posttransplant patients can be challenging due to the concurrent requirement for immunosuppressive medication, and the difficulties and risks of using other locoregional therapies such as ablation or chemoembolization.

SBRT enables the precise delivery of a high dose of radiation to the tumor in a limited number of fractions. This allows for a higher biologically effective dose so that the HCC is ablated without a significant increase in liver toxicity, allowing for a higher therapeutic ratio [10]. Previous studies have shown the safety and efficacy of SBRT in tumor control in the native liver with an in-field control rate of $68-98 \%[10,11]$.

In this report, we describe the successful treatment of recurrent HCC in a transplanted liver with SBRT. Our patient tolerated his course of radiotherapy well with no significant acute or late toxicity despite having received SBRT prior to transplant. Though tumor recurrence in the transplanted liver continues to be a significant cause of morbidity for patients with HCC, on follow-up, our patient continues to be in complete remission with no significant signs of radiation-related toxicity. We believe that SBRT is a safe and effective modality for the treatment of recurrent HCC following liver transplantation.

\section{Acknowledgements}

The authors thank Ms. Laura Finger for editorial assistance.

\section{Disclosure Statement}

The authors declare no conflicts of interest.

\section{References}

1 Parkin DM, Bray F, Ferlay J, Pisani P: Global cancer statistics, 2002. CA Cancer J Clin 2005;55:74-108.

2 Mazzaferro V, Llovet JM, Miceli R, Bhoori S, Schiavo M, Mariani L, Camerini T, Roayaie S, Schwartz ME, Grazi GL, Adam R, Neuhaus P, Salizzoni M, Bruix J, Forner A, De Carlis L, Cillo U, Burroughs AK, Troisi R, Rossi M, Gerunda GE, Lerut J, Belghiti J, Boin I, Gugenheim J, Rochling F, Van Hoek B, Majno P: Predicting survival after liver transplantation in patients with hepatocellular carcinoma beyond the Milan criteria: a retrospective, exploratory analysis. Lancet Oncol 2009;10:35-43.

-3 Shin WY, Suh KS, Lee HW, Kim J, Kim T, Yi NJ, Lee KU: Prognostic factors affecting survival after recurrence in adult living donor liver transplantation for hepatocellular carcinoma. Liver Transpl 2010;16:678-684.

-4 El-Serag HB, Rudolph KL: Hepatocellular carcinoma: epidemiology and molecular carcinogenesis. Gastroenterology 2007;132:2557-2576.

5 Parkin DM, Pisani P, Ferlay J: Global cancer statistics. CA Cancer J Clin 1999;49:33-64.

6 Yoo HY, Patt CH, Geschwind JF, Thuluvath PJ: The outcome of liver transplantation in patients with hepatocellular carcinoma in the United States between 1988 and 2001: 5-year survival has improved significantly with time. J Clin Oncol 2003;21:4329-4335.

-7 Schlitt HJ, Neipp M, Weimann A, Oldhafer KJ, Schmoll E, Boeker K, Nashan B, Kubicka S, Maschek H, Tusch G, Raab R, Ringe B, Manns MP, Pichlmayr R: Recurrence patterns of hepatocellular and fibrolamellar carcinoma after liver transplantation. J Clin Oncol 1999;17:324-331. 


\section{Case Reports in Oncology}

\begin{tabular}{l|l}
\hline Case Rep Oncol 2014;7:18-22 & \\
\hline DOI: 10.1159/000357801 & $\begin{array}{l}\text { ○ 2014 S. Karger AG, Basel } \\
\text { www.karger.com/cro }\end{array}$ \\
\hline
\end{tabular}

Mazloom et al.: Stereotactic Body Radiation Therapy as a Bridge to Transplantation and for Recurrent Disease in the Transplanted Liver of a Patient with HCC

8 Regalia E, Fassati LR, Valente U, Pulvirenti A, Damilano I, Dardano G, Montalto F, Coppa J, Mazzaferro V: Pattern and management of recurrent hepatocellular carcinoma after liver transplantation. J Hepatobiliary Pancreat Surg 1998;5:29-34.

-9 Roayaie S, Schwartz JD, Sung MW, Emre SH, Miller CM, Gondolesi GE, Krieger NR, Schwartz ME: Recurrence of hepatocellular carcinoma after liver transplant: patterns and prognosis. Liver Transpl 2004;10:534-540.

10 Huang WY, Jen YM, Lee MS, Chang LP, Chen CM, Ko KH, Lin KT, Lin JC, Chao HL, Lin CS, Su YF, Fan CY, Chang YW: Stereotactic body radiation therapy in recurrent hepatocellular carcinoma. Int J Radiat Oncol Biol Phys 2012;84:355-361.

-11 Kwon JH, Bae SH, Kim JY, Choi BO, Jang HS, Jang JW, Choi JY, Yoon SK, Chung KW: Long-term effect of stereotactic body radiation therapy for primary hepatocellular carcinoma ineligible for local ablation therapy or surgical resection. Stereotactic radiotherapy for liver cancer. BMC Cancer 2010;10:475.

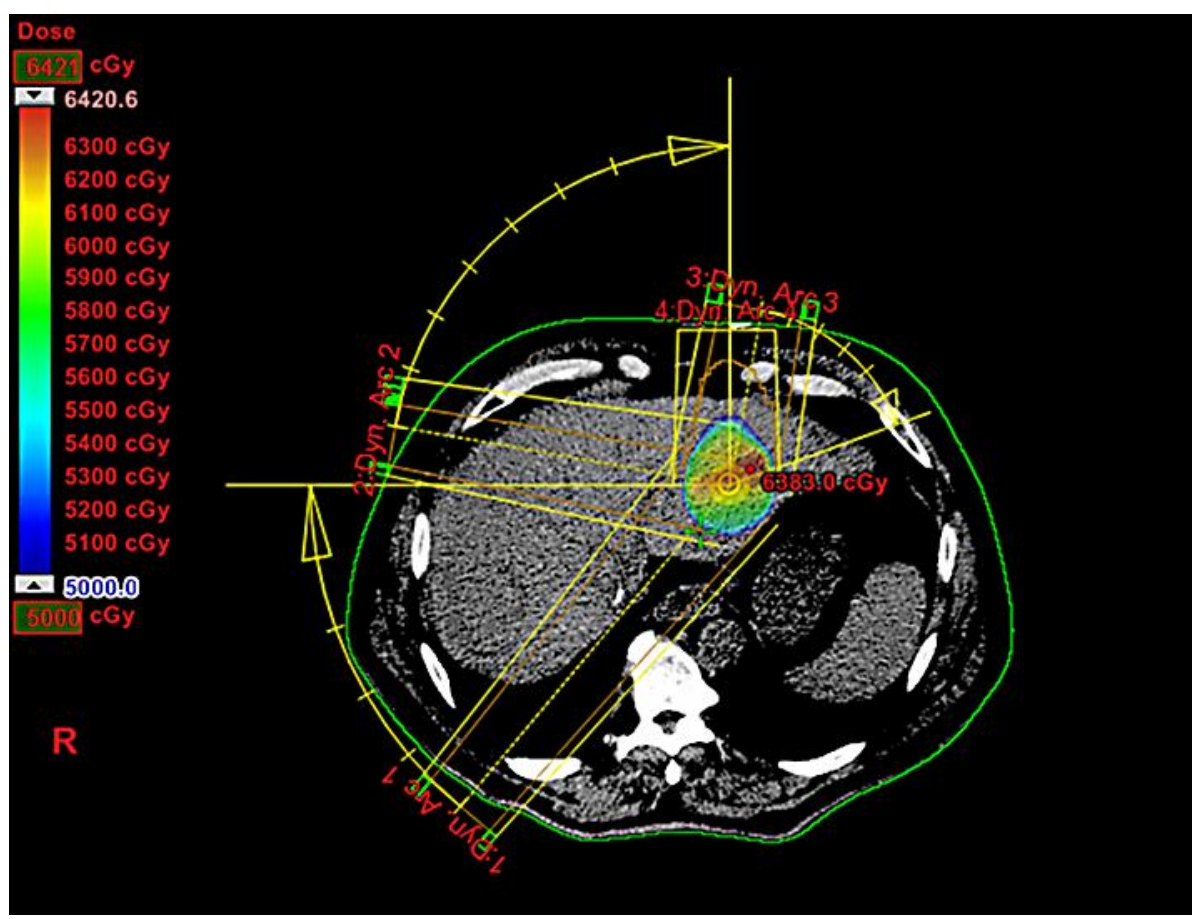

Fig. 1. SBRT plan for treatment of recurrent disease in the transplanted liver. 


\section{Case Reports in Oncology}

Case Rep Oncol 2014;7:18-22

DOI: $10.1159 / 000357801$

Mazloom et al.: Stereotactic Body Radiation Therapy as a Bridge to Transplantation

and for Recurrent Disease in the Transplanted Liver of a Patient with HCC

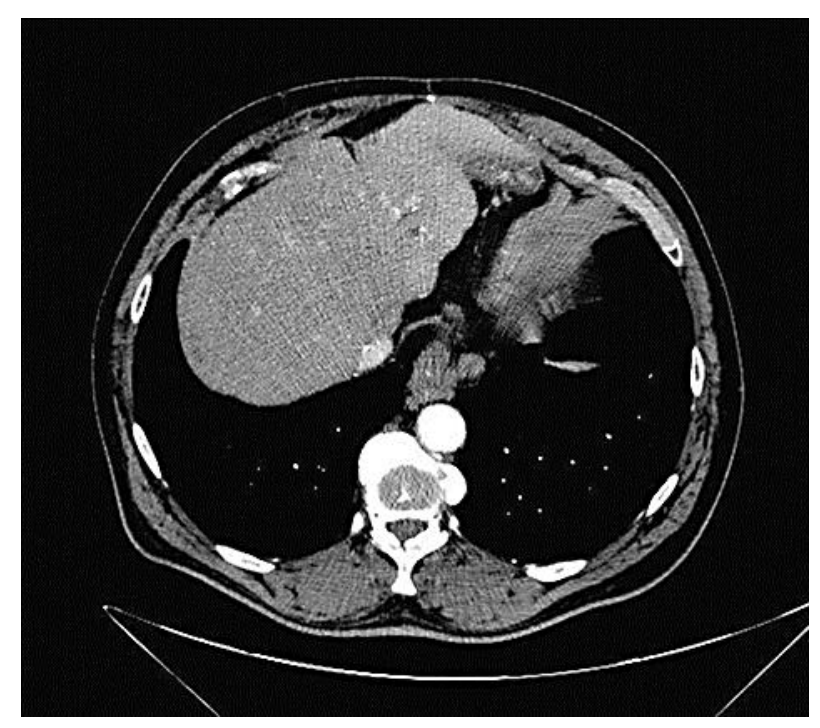

Fig. 2. CT scan 1 year after SBRT showing complete remission of the treated lesion. 